\title{
Las madres y padres, los menores e Internet. Estrategias de mediación parental en España
}

\section{Parents, minors and the internet. Parental mediation strategies in Spain}

\author{
Maialen Garmendia Larrañaga1. Universidad del País Vasco \\ Miguel Ángel Casado del Río. Universidad del País Vasco \\ Gemma Martínez Fernández. Universidad del País Vasco \\ Carmelo Garitaonandia Garnacho. Universidad del País Vasco
}

Recibido: 8-V-2013 - Aceptado: 30-VII-2013

Resumen:

Las nuevas tecnologías, y en particular internet, suponen un reto para la actividad educadora de los padres. El presente artículo pretende mostrar el modo en el que los padres y las madres afrontan esta situación a partir del análisis de las estrategias de mediación que aplican a sus hijas e hijos en el uso de internet. Los resultados que se muestran se basan en los datos de la encuesta realizada por la red europea EU Kids Online $^{2}$ en España. La encuesta en España se realizó sobre una muestra de 1.024 menores de entre 9 y 16 años, y uno de sus padres, aquel de los dos "que estuviese más implicado o tuviese un mayor conocimiento de la actividad que su hijo o hija desarrollaba en internet”. Las familias en las que se desarrollaron las entrevistas se seleccionaron a partir de direcciones escogidas a través del procedimiento de rutas aleatorias. Las entrevistas tuvieron lugar durante el año 2010. Los datos evidencian un uso muy extendido de estrategias de mediación activa, tanto en el uso como para la seguridad en internet, y restrictiva y una escasa presencia de las estrategias de carácter tecnológico o de seguimiento.

Palabras clave:

Mediación, internet, menores, padres, alfabetización mediática.

Abstract:

New technologies, and particularly the internet, mean a new challenge for parents' education activity in the last decade. This article tries to show the way parents cope with this responsibility through using different strategies in order to mediate their children's use of the internet. The results shown have been drawn from the data gathered by the survey carried by the EU Kids Online network in Spain. This survey interviewed 1.024 children aged between 9 and 16 and one of his/her parents, "the one who was more involved in the child's online activity". The addresses of the families surveyed were randomly selected using Random Walk procedures. Both, child and his/her mother or father were interviewed face-to-face and the child answered also a self completion questionnaire for sensitive questions concerning online risks. The key findings show that active strategies -related to the child's use of the internet as well as the child's internet safety-and restrictive strategies-basically related to the child's privacy issues-are very widely used among Spanish parents, whereas technical or monitoring strategies' use is very scarce.

Keywords:

Mediation, internet, minors, parents, media literacy.

1 Los autores son investigadores de la red de investigación EU Kids Online en España (http://www.lse.ac.uk/media@lse/research/EUKidsOnline/Home.aspx).

2 EU Kids Online es una red de investigadores europeos instituida en 2006. Su primer proyecto se desarrolló entre 2006 y 2009. Su obje- 


\section{Introducción}

El proceso de adopción de las nuevas tecnologías en el hogar (Silverstone y Hirsch, 1992; Haddon y Silverstone, 1992) reflejado en el creciente acceso y uso de internet por parte de los menores se ha convertido en motivo de preocupación tanto para políticos, como para familias, y el público en general (Hasebrink et al., 2009). Por una parte, la aparición y expansión de Internet en la década de los 90 y el creciente y diverso uso que los individuos hacen de esta nueva tecnología hacen que se haya suscitado un profundo interés en el seno de la comunidad científica. Por otra parte, niños, jóvenes y adultos ven en Internet diferentes y a la vez encontradas posibilidades. Son muchos y muy distintos los factores que influyen en las desiguales percepciones que se tienen acerca de la red. Los menores suelen identificar Internet como fuente de oportunidades y de riesgos fácilmente evitables. En este sentido, la mayoría de los estudios publicados a nivel nacional y europeo desde el año 2007 coinciden en que una de las mayores preocupaciones que los menores tienen frente a la red son los virus y los problemas técnicos del propio ordenador (Garitaonandia y Garmendia, 2007; Eurobarómetro cualitativo, 2007; Inteco, 2009; Livingstone y Bobber, 2005).

Esta confianza, en determinadas ocasiones excesiva e injustificada, que presentan los menores frente a Internet, choca de frente con la desconfianza y el temor que muchos padres profesan por lo que les pueda ocurrir a sus hijos en Internet. Los menores confían en sus habilidades y en su experiencia para poder enfrentarse a cualquier riesgo potencial o real en la red. Los padres, en cambio, suelen considerarse a sí mismos como inexpertos y poco habilidosos en el manejo de las herramientas online, lo que les provoca cierta inseguridad para detectar los riesgos en la red y así poder ayudar a sus hijos. Este desconocimiento puede repercutir en la percepción del riesgo que ellos tienen (Aslanidou y Menexes, 2008).

Estas percepciones por parte de ambos grupos están contribuyendo a que, en muchos casos, la sociedad haya asumido como válida la idea de que los menores son capaces de controlar Internet y los padres no se enteran de nada, cuando existen datos que demuestran lo contrario (Hasebrink et al., 2009; Duimiel y De Haan, 2009). En este contexto uno de los principales retos para los padres y madres consiste en cómo regular el uso que los más pequeños hacen de la red con el fin de evitar actividades de riesgo y, al mismo tiempo, fomentar aquéllas que contribuyan a su desarrollo personal e intelectual (O`Neill, 2011).

A pesar de la importancia de la actividad de los padres y madres, no podemos olvidar que la relación de los menores con internet es compleja y en ella intervienen muchos factores más. Livingstone et al. (2011) plantean está relación en función de tres niveles de influencia trazando la secuencia entre uso de internet y posible daño. Así, hay que considerar en primer lugar algunos factores de tipo demográfico tales como la edad, el género, el estatus socioeconómico, y factores psicológi-

tivo principal consistía en reflexionar de forma sistemática sobre la investigación realizada sobre menores e Internet en 21 países europeos, identificando los hallazgos clave así como las principales lagunas de investigación. En su segundo proyecto se desarrolló el trabajo de campo en 25 países europeos cuyos resultados se presentan en este artículo. 
cos como los problemas emocionales y la tendencia a correr riesgos. Los factores psicológicos se están revelando además como una clave muy importante en relación con los riesgos ya que su incidencia muestra en muchos casos más probabilidad de llegar a experimentar algún daño a través de la red (Wolak, 2008).

Los factores sociales serían el segundo nivel de influencia, entre ellos podemos considerar las actividades de los padres, profesorado o las amistades que median las experiencias online y offline de los niños y niñas. Y, por último en un tercer nivel, el propio contexto nacional del que se derivan una gama de factores económicos, sociales y culturales que contribuyen a conformar la experiencia online del menor y que influyen, por ejemplo, en el modo en el que se aborda la relación de los menores con internet en cada país.

Valcke et al. (2011) clasifican las diferentes acciones que se puede realizar para promover un uso seguro de internet entre los niños y niñas en cuatro grandes grupos: las campañas de concienciación; la promoción de herramientas de software para filtrar contenidos; las aproximaciones a partir del propio sistema educativo y la supervisión de los padres. En el caso español se han dado importantes pasos en el ámbito de las campañas de concienciación con la implicación de numerosos agentes, que van desde diversas organizaciones no gubernamentales hasta los cuerpos de seguridad -tanto a nivel estatal como autonómico-, o las agencias de protección de datos que han desarrollado una labor clave en España en la promoción de conductas responsables en el uso de los datos personales en las redes sociales.

Las herramientas de software son, sin embargo, una asignatura pendiente de cara a la búsqueda de un entorno más seguro, tal y como se muestra en posteriores apartados de este trabajo. Entre los países europeos estudiados, España es uno de los que presenta un menor uso de estas herramientas.

El sistema educativo, por su parte, está dando importantes pasos en la incorporación de Internet y las nuevas tecnologías en el currículum escolar de los alumnos y, paralelamente a ese aprendizaje, se está realizando una importante labor de promoción de un uso seguro de internet. Es importante recordar que el colegio es el canal más eficiente y justo para poder llegar a todos los niños y niñas. Sin embargo, la limitación de los recursos -tanto técnicos como humanos- hace que aún no se haya alcanzado el nivel deseable en las competencias de seguridad de los menores (Garmendia et al., 2012), ni en la mayoría de los aspectos relevantes de la alfabetización mediática (Ferrés, Aguaded y García, 2012). En cualquier caso, el papel de la escuela ha de ir más allá de "una mera capacitación tecnológica” y debe conducir a una alfabetización crítica, dignificante y liberadora” (Martín y Tyner, 2012: 32).

Como se ha señalado son numerosos los agentes que intervienen en este proceso (Valcke, De Wever, Van Keer y Schellens, 2011), pero cada vez es mayor el consenso social en relación con el protagonismo de los padres y madres. El último informe de EU Kids Online señalaba que "el rol de los padres para proteger al menor en internet es esencial y se ve reforzado por el hecho de que el hogar es el lugar más común de uso de internet y los padres son el primer punto de contacto que los 
menores tienen cuando experimentan alguna dificultad online" (Livingstone et al., 2011: 145). En España, según los datos del informe de EU Kids Online, (Garmendia et al., 2011) el 84\% de los menores -usuarios de internet- afirma utilizar internet en casa, prácticamente el mismo porcentaje que se da de media para los países incluidos en el estudio (85\%). La mayoría (63\%) lo hace en el salón (u otra habitación común), pero un $42 \%$ también puede usar internet en su propio cuarto (o en otro privado del hogar). El segundo lugar más común para el uso de internet es el colegio (70\%). Esto convierte al colegio en un lugar muy importante para recibir el consejo y la orientación de los profesores.

Cada localización en el uso de internet implica unas convenciones sociales particulares en lo que se refiere a libertad, privacidad, sociabilidad y vigilancia. Hasta hace muy poco el acceso a internet se limitaba a los ordenadores de sobremesa, y los padres podían ser aconsejados mediante diversas campañas para ubicar el ordenador en un lugar común del hogar o para instalar herramientas de filtrado o monitorización. Con el desarrollo de las tecnologías móviles y los dispositivos personalizados, las posibilidades de conexión de los menores se han diversificado. Tanto en su habitación o mediante móviles u otros dispositivos portátiles, los menores pueden evitar la supervisión y usar internet de manera totalmente privada. Al margen de esto, mientras que en los colegios el uso de internet está generalmente supervisado, los cibercafés, muy populares en algunos países, también proporcionan al menor un acceso sin ninguna supervisión.

Diversas evidencias empíricas avalan la aplicación de estrategias de mediación parental orientadas a potenciar un uso eficaz de internet entre los menores en diversos países europeos (Haddon, 2011; Livingstone y Helsper, 2008; Kirwil et al., 2009; Oswell, 1999). Además, no podemos obviar otras cuestiones que contribuyen a reforzar la importancia de la mediación parental en el uso de internet. En primer lugar, se ha detectado una tendencia general a sobredimensionar los efectos negativos que las nuevas tecnologías pueden tener sobre los menores, en parte propiciado por la actividad de los medios de comunicación (Ponte, Bawens y Mascheroni, 2009: 163). Este hecho ha contribuido a generar lo que se conoce como pánico social o moral panic (Hasebrink et al., 2009). Dicho fenómeno se ha acentuado especialmente con la extensión del uso de las redes sociales que ha propiciado un aumento de la preocupación entre los padres. En segundo lugar, los investigadores tienden a identificar al menor como elemento vulnerable, tanto en su papel de usuario de internet como en el propio proceso de mediación parental (Byron, 2008 y Hasebrink et al. 2009). Este hecho puede estar contribuyendo al incremento de la mencionada preocupación (Livingstone y Bober, 2006). Tras la noción de menor como sujeto vulnerable, suele estar implícita la idea de los efectos negativos derivados del uso de estas nuevas tecnologías, bien sea sobre su comportamiento, bienestar o seguridad. Sin embargo, hay evidencias empíricas que han demostrado la necesidad de evitar la idea del menor como vulnerable y víctima, así como el determinismo tecnológico según el cual las nuevas tecnologías son identificadas como causantes directas de efectos negativos sobre el individuo (Anderson y Bushman 2001; Buckingham, 2000; Livingstone, 2007). En este sentido, resulta clave la distinción entre los conceptos de riesgo y daño, ya que no todas las actividades catalogadas como arriesgadas para el menor le causan necesariamente daño. 
Teniendo en cuenta las anteriores premisas y atendiendo a las evidencias empíricas que demuestran que las estrategias de mediación parental pueden influir -junto con otros factores- en las actividades desarrolladas por los menores (Dürager y Livingstone, 2012), el objetivo del presente artículo consiste en analizar cada una de las estrategias de mediación aplicadas por los padres en España cuando los menores usan internet.

Considerando estos aspectos en el presente artículo se plantean las siguientes cuestiones de investigación:

RQ1: ¿Cuáles son las estrategias de mediación parental más empleadas por los padres y madres en España?

RQ2: ¿De qué manera influye el sexo y la edad de los menores en la aplicación de estas estrategias?

RQ3: ¿En qué lugar se sitúa España en relación con el resto de países europeos ${ }^{3}$ que participan en la investigación en la aplicación de estrategias de mediación parental?

\section{Metodología}

Las clasificaciones de estrategias de mediación parental para internet más frecuentemente utilizadas tienen su origen en las que en su momento se emplearon en relación con el estudio de la mediación del uso de la televisión (Van der Voort, Nikken y Van Lil, 1992; Valkenburg, Krcmar Peeters y Marseille, 1999; Nathanson, 2001). En nuestro caso tomamos la clasificación de Livingstone y Helsper (2008) por considerar que es la que mejor se adapta a los hábitos de uso de los menores. Las autoras dividen las estrategias de mediación parental en internet en cinco categorías: (I) estrategias de co-uso o la mediación activa en el uso -la madre o el padre está presente, incluso compartiendo actividades con el menor-, (II) la mediación activa en la seguridad -la madre o el padre explican contenidos para guiar al menor-, (III) la mediación restrictiva -los padres establecen reglas para restringir el uso del menor-, (IV) el seguimiento o monitorización -los padres comprueban los datos disponibles sobre la navegación del menor-y, (V) la mediación técnica -el uso de software para filtrar o restringir el uso del menor de internet-.

Así, en el presente análisis, se distingue, por un lado, la mediación activa en el "uso de internet en general" que implica una mayor presencia de los progenitores durante el uso de los menores de internet y, por otro, la mediación activa de la "seguridad en Internet” en cuyo caso los progenitores guían al menor en el uso, pero no están necesariamente presentes. Los resultados que se presentan provienen de la encuesta realizada dentro del proyecto de investigación financiado por el Safer Internet Programme de la Comisión Europea EU Kids Online. Este proyecto ha llevado a cabo una encuesta entre más de 25.000 menores de entre 9 y 16 años y a sus madres o padres en Europa para saber qué actividades desarrollan en

3 Los países participantes en este proyecto son: Alemania, Austria, Bélgica, Bulgaria, Chipre, Dinamarca, Eslovenia, Estonia, España, Finlandia, Francia, Grecia, Hungría, Irlanda, Italia, Lituania, Noruega, los Países Bajos, Polonia, Portugal, la República Checa, el Reino Unido, Rumanía, Suecia y Turquía. 
internet, con qué riesgos se han encontrado y, en el caso de los padres y madres conocer qué hacen para intentar minimizar la exposición a los riesgos por parte de sus hijos e hijas. La encuesta realizada en España se llevó a cabo entre mayo y julio de 2010 a un total de 1.024 menores y a su madre o padre, aquel de los dos "que estuviese más implicado o tuviese un mayor conocimiento de la actividad que su hijo o hija desarrollaba en internet”. Las familias en las que se realizaron las entrevistas se seleccionaron a partir de direcciones escogidas a través del procedimiento de rutas aleatorias -el entrevistador elige un hogar al azar teniendo en cuenta las limitaciones propias de la estratificación-. En cada una de las direcciones donde se accedió a realizar la entrevista se eligió aleatoriamente un niño de entre los niños de la vivienda que tuvieran entre 9 y 16 años y usaran Internet, teniendo en cuenta el cumpleaños más reciente de entre los niños elegibles.

Las muestras fueron estratificadas por Comunidad Autónoma y nivel de urbanización y los puntos de muestreo se seleccionaron a través de los registros completos de las unidades geográfico/ administrativas ${ }^{4}$. Así, todas las Comunidades Autónomas de España fueron incluidas en la muestra.

Tanto las entrevistas a padres y madres como a los y las menores se realizaron cara a cara; en el caso de los y las menores también había una parte de cuestionario auto-rellenable para preguntas sensibles relativas a riesgos online. En el proceso de diseño de los diversos cuestionarios se realizaron diversos tests cognitivos con el fin de evitar los errores sistemáticos de sesgo -que proporcionan medidas sistemáticamente mayores o menores que los valores reales-. Sin embargo, por el mero hecho de no haber entrevistado a todos los menores que constituyen el ámbito de estudio correspondiente, se asume que puede haber cierta diferencia entre los datos obtenidos en la investigación y los valores reales o error de muestreo. La muestra en su conjunto fue diseñada para los 25 países europeos incluidos en la investigación y su error máximo era de +/- 0,5\%. Para los resultados obtenidos a través del trabajo de campo realizado en España el margen de error máximo es de $+/-3 \%$, aunque este error puede oscilar en función de los valores de los porcentajes obtenidos y también cuando se refieren a partes de la muestras relativamente reducidas dentro del ámbito nacional -por ejemplo los menores que han experimentado un determinado riesgo-.

\section{Resultados}

A partir de la clasificación de mediaciones presentada, se preguntó a padres y madres sobre sus actitudes o las acciones que desarrollaban en relación al uso que sus hijos e hijas hacen de internet, y a los menores sobre las actividades de mediación que sus padres realizaban. Así, cada una de las preguntas sobre estos aspectos respondía a un tipo concreto de mediación. En la exposición de los resultados se presentarán agrupadas dentro de cada tipo específico de mediación para

4 Una explicación más detallada de la metodología empleada en el proyecto está disponible en la página web de la red de investigación: http://www.lse.ac.uk/media@lse/research/EUKidsOnline/EU\%20Kids\%20II\%20\%282009-11\%29/Survey/Survey\%20documents.aspx 
poder observar de forma más clara la importancia relativa de cada uno de los tipos de estrategias entre los padres y las madres. Tanto las respuestas de los progenitores como las de los hijos son de indudable valor para el estudio de estas mediaciones. Sin embargo, teniendo en cuenta la divergencia entre estos dos tipos de respuesta, en este trabajo se ha optado por presentar las respuestas de los menores, porque los padres en sus respuestas tienden a sobreestimar su mediación debido a la presión de lo "políticamente correcto" (Gentile, Nathanson, Rasmussen, Reimer, y Walsh, 2012; Livingstone y Bober, 2006; Wang, Bianchi, y Raley, 2005). Estos últimos, por ejemplo, llegaban a hablar de un nivel del $40 \%$ de desacuerdo entre padre e hijos, fundamentalmente por el hecho de que los menores no reconocen muchas de las normas que los padres y madres dicen haber establecido.

En la presentación de resultados y de cara a responder a la tercera cuestión de investigación planteada, también se incluyen los datos relativos a la incidencia media de esas mediaciones tomados del informe final del proyecto EU Kids Online (Livingstone, Haddon, Görzig, y Ólafsson, 2011), para su comparación con los datos referidos a España.

\subsection{Mediación activa}

Por mediación activa se entiende el uso de internet por el menor mientras el padre o madre está presente o cerca del menor cuando usa internet, animándole, compartiendo o comentando sus actividades en internet. Esta modalidad de mediación se concretó en las siguientes preguntas a los menores:

¿Cuáles de las siguientes acciones realizan tus padres mientras tú utilizas internet?:

- Hablar contigo sobre lo que haces en Internet.

- Estar cerca mientras navegas por internet.

- Animarte a explorar y aprender cosas nuevas en internet.

- Sentarse contigo mientras usas internet.

- Realizar actividades compartidas contigo en internet. 
Tabla 1. Mediación activa de los padres y madres en el uso de internet del menor, según el menor

\begin{tabular}{|l|c|c|c|c|c|c|}
\hline \multirow{2}{*}{ \% que afirma que sus padres o madres } & \multicolumn{4}{|c|}{ España } & Europa \\
\hline Hablan con él o ella sobre lo que hace en Internet & \multicolumn{2}{|c|}{$9-12$ años } & \multicolumn{2}{|c|}{$13-16$ años } & \multirow{2}{*}{ Todos } & \multirow{2}{*}{ Todos } \\
\cline { 2 - 7 } & Niños & Niñas & Niños & Niñas & & \\
\hline Están cerca mientras navega por internet & 72,2 & 82,3 & 55,9 & 74,1 & 70,5 & 69,6 \\
\hline Anima a explorar y aprender cosas nuevas en internet & 76,2 & 77,7 & 57,7 & 71,1 & 70 & 57,7 \\
\hline Se sientan con él mientras usa internet & 56,3 & 53,5 & 38,6 & 47,2 & 49 & 47,3 \\
\hline Realiza actividades compartidas con él en internet & 59,8 & 57,8 & 39,6 & 47,5 & 50,6 & 43,8 \\
\hline Al menos una de estas & 51,6 & 53,1 & 32,1 & 38,9 & 43,4 & 42,3 \\
\hline
\end{tabular}

Fuente: resultados de la encuesta EU Kids Online España y Livingstone et al. 2011

En la tabla 1 se puede observar cómo, de manera similar a como ocurre en Europa, la forma más habitual de mediación activa es hablar con el menor sobre lo que hace en internet. La segunda forma de mediación activa en el uso más extendida según los menores es permanecer cerca de ellos mientras navegan en internet. En este caso, el porcentaje es también del $70 \%$, superior a la media europea ${ }^{5}$.

Aunque, en general, se puede decir que la mediación activa en el uso está muy extendida entre los padres es necesario señalar que se dan notables diferencias tanto en relación con el género como con la edad de los menores. En todos los casos, los menores de entre 9 y 12 años afirman recibir este tipo de mediación con mayor frecuencia que los demás grupos de edad. Con respecto al género, las niñas presentan una mayor frecuencia de mediación que los niños, particularmente entre los 13 y los 16 años. La tendencia observada con la edad responde a un patrón similar al observado en la media europea, sin embargo, en relación con el género la diferencia entre la incidencia de la mediación entre niños y niñas en España es mucho más acentuada.

\subsection{Mediación activa en la seguridad en internet}

En lo que se refiere a la mediación activa sobre la seguridad en internet, la diferencia fundamental con respecto a la mediación activa en el uso se estableció en la participación concreta del padre o la madre en actividades directamente relacionadas con la seguridad en internet. Esta modalidad comprende las siguientes acciones:

\footnotetext{
5 La media europea corresponde a la media general para los 25 países incluidos en el estudio.
} 
¿Cuáles de las siguientes acciones realizan tus padres mientras tú utilizas internet?:

- Explicarte por qué unas webs son buenas o malas.

- Ayudarte cuando algo es difícil de hacer o encontrar en internet.

- Indicarte modos de usar internet de manera segura.

- Indicarte el modo de comportarte con otras personas en internet.

- Explicarte qué hacer si algo te molesta en internet.

- Ayudarte en el pasado cuando algo te ha molestado en internet.

Tabla 2. Mediación activa de padres y madres en la seguridad de internet del menor, según el menor

\begin{tabular}{|l|c|c|c|c|c|c|}
\hline \multirow{2}{*}{ \% que afirma que sus padres o madres } & \multicolumn{3}{|c|}{ España } & \multirow{2}{*}{ Europa } \\
\hline & \multicolumn{2}{|c|}{$9-12$ años } & \multicolumn{2}{|c}{$13-16$ años } & \multirow{2}{*}{ Todos } \\
\cline { 1 - 6 } Explicado por qué unas webs son buenas o malas & Niños & Niñas & Niños & Niñas & & \\
\hline $\begin{array}{l}\text { Ayudado cuando algo es difícil de hacer o encontrar en in- } \\
\text { ternet }\end{array}$ & 76,9 & 79,5 & 69,1 & 70,8 & 73,8 & 67,5 \\
\hline Indicado modos de usar internet de manera segura & 70,4 & 73,7 & 54,1 & 61 & 65,2 & 66,2 \\
\hline $\begin{array}{l}\text { Indicado el modo de comportarse con otras personas en } \\
\text { internet }\end{array}$ & 58,8 & 58,3 & 54 & 63,9 & 58,6 & 55,7 \\
\hline Explicado qué hacer si algo te molesta en internet & 53,6 & 60,1 & 48 & 60,5 & 55,3 & 52,2 \\
\hline $\begin{array}{l}\text { Ayudado en el pasado cuando algo te ha molestado en in- } \\
\text { ternet }\end{array}$ & 38,1 & 39,7 & 38 & 39,2 & 38,7 & 35,5 \\
\hline Al menos una de las anteriores & 89,4 & 92,6 & 83 & 91,7 & 89 & 85,6 \\
\hline
\end{tabular}

Fuente: resultados de la encuesta EU Kids Online España y Livingstone et al. 2011

Explicar por qué unas páginas son buenas o malas (73,8\%), indicar el modo de usar internet de manera segura (68,8\%) y ayudar al menor cuando algo es difícil de hacer o de encontrar en internet $(65,2 \%)$ son las formas de mediación activa para la seguridad en internet más frecuentes. Además, más de la mitad de los padres indican a sus hijos el modo de comportarse con otras personas en internet (58,6\%) y les explican qué hacer si algo les molesta en internet (55,3\%) y, en menor medida, $(38,7 \%)$ han ayudado a sus hijos cuando éstos se han sentido molestos por algo que les ha ocurrido en internet. 
En general, en todos los tipos de mediaciones las niñas presentan una mayor frecuencia de mediación que los niños, pero en algunos tipos estas diferencias son especialmente notables. Así, el 64\% de las niñas entre 13 y 16 años afirman que sus padres les indicaron el modo de comportarse en internet frente al 54\% de los niños y al 60\% de las niñas se le indicó qué podían hacer en caso de encontrar algo que les resultase molesto en internet, frente al $48 \%$ de los niños. En cuanto a la edad, los menores más pequeños reciben más atención para evaluar las páginas web y para usar internet de manera segura. Con respecto a los datos de la media europea, España presenta un nivel ligeramente superior de mediación activa en la seguridad para todas las cuestiones.

\subsection{Mediación restrictiva}

A los padres se les ha aconsejado asiduamente el establecimiento de normas o restricciones para controlar el uso que sus hijos hacen de internet. Estas pueden ser simples prohibiciones -diciendo a los hijos que no pueden llevar a cabo determinada actividad en internet o diciéndoles que sólo pueden realizarla con permiso o bajo supervisión-. Ambos tipos de estrategias han sido consideradas como acciones de mediación restrictiva y se contraponen con la ausencia de cualquier tipo de norma en esas actividades (tabla 3). Dentro de este tipo de estrategia de mediación se preguntaba a los menores si sus padres les habían establecido alguna norma sobre estos aspectos:

- Dar información personal a otros en internet.

- Subir videos, imágenes o música para compartir con otros.

- Descargar música o películas en internet.

- Tener un perfil propio en una red social.

- Ver videoclips en internet.

- Usar mensajería instantánea.

Tabla 3. Acciones de mediación restrictiva de padres y madres según los menores

\begin{tabular}{|c|c|c|c|c|c|c|}
\hline \multirow{3}{*}{ 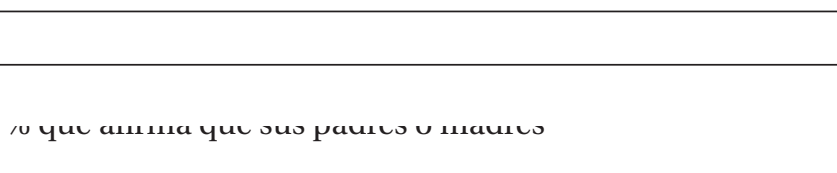 } & \multicolumn{5}{|c|}{ España } & \multirow{3}{*}{$\begin{array}{l}\text { Europa } \\
\text { Todos }\end{array}$} \\
\hline & \multicolumn{2}{|c|}{ 9-12 años } & \multicolumn{2}{|c|}{ 13-16 años } & \multirow{2}{*}{ Todos } & \\
\hline & Niños & Niñas & Niños & Niñas & & \\
\hline Dar información personal a otros en internet & 95,4 & 96,9 & 84,8 & 83,6 & 90 & 85,4 \\
\hline Subir videos, imágenes o música para compartir con otros & 82,3 & 84 & 39 & 41,1 & 60 & 62,8 \\
\hline Descargar música o películas en internet & 68,1 & 65,4 & 24,2 & 24 & 43,8 & 56,7 \\
\hline
\end{tabular}




\begin{tabular}{|l|c|c|c|c|c|c|}
\hline \multirow{2}{*}{ \% que afirma que sus padres o madres } & \multicolumn{4}{|c|}{ España } & Europa \\
\hline Tener un perfil propio en una red social & \multicolumn{2}{|c|}{$9-12$ años } & \multicolumn{2}{|c|}{$13-16$ años } & \multirow{2}{*}{ Todos } & \multirow{2}{*}{ Todos } \\
\cline { 2 - 7 } & Niños & Niñas & Niños & Niñas & & \\
\hline Ver videoclips en internet & 75,2 & 79,2 & 24,3 & 26 & 49,1 & 47,0 \\
\hline Usar mensajería instantánea & 54,4 & 50,7 & 15 & 14,6 & 32,6 & 38,6 \\
\hline Al menos una de las anteriores & 50,6 & 50,5 & 17,3 & 11,8 & 31,2 & 38,2 \\
\hline
\end{tabular}

Fuente: resultados de la encuesta EU Kids Online España y Livingstone et al. 2011.

La mayoría de las normas se establecen en relación con la difusión de información personal, el 90\% de los menores afirman tener restricciones en este terreno. La siguiente acción más regulada es la subida a internet de diferentes contenidos (60\%), aunque esta cifra probablemente se refiere sobre todo a las reglas relativas a imágenes o vídeos de los propios menores (tabla 4).

En el caso de la descarga de contenidos (música o películas) se produce una importante diferencia entre la media europea y los datos referidos a España. Según la media europea, el 57\% de los menores afirman tener restricciones o prohibición para esto, en España este porcentaje es del 43,8\%. Además, cerca de la mitad de los menores afirman tener restricciones para el acceso a redes sociales $(49,1 \%)$ y cerca de un tercio tienen algún tipo de restricción en el uso de redes de mensajería instantánea o para ver videoclips.

\subsection{Seguimiento}

Internet conserva un historial de las acciones realizadas, de manera que los padres pueden hacer el seguimiento de las actividades de sus hijos en internet durante o, más frecuentemente, después de su uso. Mientras la mediación restrictiva puede generar discusiones en el hogar, el seguimiento puede generar reticencias en la medida en que pueden socavar las relaciones de confianza entre padres e hijos al adentrarse en la esfera personal de éstos.

Dentro de la estrategia de seguimiento se preguntaba a los menores si sus padres o madres comprobaban los siguientes puntos de uso de internet ${ }^{6}$ :

- Las páginas que has visitado.

6 En el caso de las estrategias de seguimiento es posible que la incidencia de estas estrategias sea superior a la manifestada por los menores ya que pueden ser acciones llevadas a cabo por los padres y madres sin el conocimiento del menor. 
- Tu perfil en una red social o una comunidad virtual.

- Qué amigos o contactos has añadido a tu perfil.

- Tus mensajes de correo electrónico o mensajería instantánea.

Tabla 4. Seguimiento del uso de internet de los menores según los menores

\begin{tabular}{|l|c|c|c|c|c|c|}
\hline \multirow{2}{*}{ \% que afirma que sus padres o madres } & \multicolumn{4}{|c|}{ España } & \multirow{2}{*}{ Europa } \\
\cline { 1 - 6 } & \multicolumn{2}{|c|}{$9-12$ años } & \multicolumn{2}{|c|}{$13-16$ años } & \multirow{2}{*}{ Todos } \\
\cline { 2 - 6 } & Niños & Niñas & Niños & Niñas & & \\
\hline Las páginas que has visitado & 52,8 & 57 & 32,8 & 37,8 & 44,2 & 46,1 \\
\hline Tu perfil en una red social o una comunidad virtual & 53,3 & 67,3 & 27,6 & 33,7 & 37,5 & 39,7 \\
\hline Qué amigos o contactos has añadido a tu perfil & 55,8 & 60,8 & 19,9 & 33,5 & 34,8 & 35,9 \\
\hline Tus mensajes de correo electrónico o mensajería instantánea & 47 & 39,2 & 15,9 & 26,6 & 29,2 & 25,4 \\
\hline Al menos uno de estos & 54,9 & 59,6 & 36,4 & 48,4 & 48,3 & 50,2 \\
\hline
\end{tabular}

Fuente: resultados de la encuesta EU Kids Online España y Livingstone et al., 2011.

Aproximadamente uno de cada dos padres emplea estrategias de seguimiento o monitorización. Esto supone que es la estrategia menos adoptada de las estudiadas. Comprobar las webs que el menor ha visitado es la forma más común de monitorización (44,2\%), probablemente por la facilidad de realizar esta acción. El control de los perfiles de las redes sociales (37,5\%), o de las personas que son añadidas a estos perfiles (34,8\%), son también estrategias de monitorización comunes, mientras que el chequeo de los mensajes de mensajería instantánea o de correo electrónico (29,2\%) es el menos extendido. Por último, hay que señalar que existen diferencias muy notables entre los grupos de edad que podrían responder a la voluntad de los padres de respetar la privacidad de los adolescentes. En general, el nivel de esta mediación en España es similar al de la media europea.

\subsection{Mediación técnica}

Al margen de estas estrategias de seguimiento, hay que tener en cuenta que también se han desarrollado algunas herramientas técnicas específicas para la mediación parental. En último lugar, se preguntó a padres e hijos por el uso de estas herramientas para la el control del uso que el menor hace de internet.

Las herramientas que se consideraban como propias de esta estrategia técnica fueron las siguientes: 
- Software para prevenir spam o virus.

- Controles parentales u otros medios para bloquear contenidos o filtrar algunas webs.

- Controles parentales u otros medios de controlar la navegación que se ha realizado.

- Un servicio o contrato que limita el tiempo que pasas en internet.

Tabla 5. Mediación técnica de padres y madres en el uso de los menores de internet, según los menores

\begin{tabular}{|l|c|c|c|c|c|c|}
\hline \multirow{2}{*}{ \% que afirma que sus padres o madres } & \multicolumn{4}{|c|}{ España } & \multirow{2}{*}{ Europa } \\
\hline & \multicolumn{2}{|c|}{$9-12$ años } & \multicolumn{2}{|c|}{$13-16$ años } & \multirow{2}{*}{ Todos } \\
\cline { 2 - 5 } & Niños & Niñas & Niños & Niñas & & 73,1 \\
\hline Software para prevenir spam o virus & 70,1 & 74,7 & 69,1 & 76,1 & 72,5 & 73,0 \\
\hline $\begin{array}{l}\text { Controles parentales u otros medios para bloquear contenidos } \\
\text { o filtrar algunas webs }\end{array}$ & 23 & 25,3 & 11,6 & 24,4 & 19,7 & 28,0 \\
\hline $\begin{array}{l}\text { Controles parentales u otros medios de controlar la navega- } \\
\text { ción que se ha realizado }\end{array}$ & 22,2 & 22,7 & 9,7 & 15,8 & 15,8 & 23,8 \\
\hline $\begin{array}{l}\text { Un servicio o contrato que limita el tiempo que pasas en inter- } \\
\text { net }\end{array}$ & 2,8 & 8,4 & 5,3 & 6,6 & 5,7 & 12,8 \\
\hline Al menos una de las anteriores & 71,1 & 75,6 & 70,9 & 76,9 & 74,4 & 74,8 \\
\hline
\end{tabular}

Fuente: resultados de la encuesta EU Kids Online España y Livingstone et al., 2011.

La forma más extendida de mediación técnica, presente en cerca de tres cuartas partes de los hogares de los encuestados $(72,5 \%)$, son los programas antivirus, aunque éstos no se dirigen tanto a la seguridad del menor como a la seguridad del propio ordenador.

Al margen de estos programas, el uso de herramientas técnicas es relativamente bajo en comparación con otras estrategias de mediación parental. Menos de un $20 \%$ de los menores afirman que sus padres utilizan programas para bloquear contenidos o filtrar webs. El 15,8\% utiliza programas específicos para hacer un seguimiento de la navegación del menor, y menos de un $6 \%$ tiene un servicio o contrato para limitar el tiempo que el menor pasa en internet. El uso en España es sensiblemente inferior al que se da en Europa en todas las cuestiones planteadas salvo en el caso del antivirus 


\section{Conclusión}

Cerca del 90\% de los menores afirma que sus padres o madres desarrollan algún tipo de estrategia de mediación activa en el uso, activa en la seguridad en internet o restrictiva. Se puede hablar por tanto de una incidencia muy alta de estas mediaciones. Estos datos generales requieren, sin embargo, una matización. Un análisis pormenorizado de las preguntas y las respuestas permite observar que son muchos menos los padres o madres que, por ejemplo, pasan tiempo con sus hijos e hijas mientras navegan (50,6\%) o que realizan actividades conjuntas con ellos en internet $(43,4 \%)$. En el caso de las estrategias restrictivas, éstas se refieren en la mayoría de los casos a la prohibición de dar información personal a través de internet. Otro tipo de restricciones consideradas tienen una incidencia mucho menor. El seguimiento o monitorización es la estrategia de mediación parental menos seguida por padres y madres en España.

En lo que se refiere al género, aunque en general no se observan grandes diferencias, en algunas preguntas concretas relativas a determinadas estrategias se observa una mayor incidencia de la mediación entre las niñas que entre los niños. Así, los padres y madres hablan más sobre las actividades de internet con las niñas que con los niños y están más cerca de ellas que de ellos cuando navegan. La estrategia de seguimiento es también más frecuente en el caso de las niñas que de los niños.

Por lo que respecta a la edad, sí se observa una reducción general de la incidencia de la mediación entre los menores de entre 13 y 16 años frente a los de entre 9 y 12. Ambos aspectos sugieren una mayor percepción de vulnerabilidad o de riesgo en relación con las niñas y aquellos menores más pequeños por parte de sus padres y madres.

En suma, del análisis de la incidencia de las diversas estrategias de mediación parental se desprende una amplia difusión de las estrategias de mediación activas tanto de la seguridad en internet -la mayoría de los padres y madres españoles habla con sus hijos e hijas menores con el fin de orientarles hacia un uso más seguro y les ayuda cuando tienen dificultades- como de la actividad de los menores -es también muy frecuente que hablen con ellos sobre lo que hacen y estén cerca mientras navegan-. No obstante, los padres y madres también utilizan estrategias de carácter restrictivo planteándoles normas relacionadas con su privacidad en internet. Estas pautas proporcionan a los padres y madres españoles cierta ventaja de cara a afrontar los retos que la conexión a internet a través de dispositivos móviles plantea en relación con la mediación o supervisión parental.

En el contexto europeo los datos que presenta España en cuanto a mediación parental dentro del estudio de EU Kids Online se sitúan muy cerca de la media europea salvo en el caso de las estrategias restrictivas donde se da una mayor incidencia que en la mayoría de los países europeos y en la mediación técnica donde el nivel es sensiblemente inferior. Estas estrategias pueden tener aspectos positivos en relación con algunos aspectos concretos, como es el caso de las normas relativas a la difusión de datos personales o el acceso a determinados contenidos, pero también pueden suponer un 
perjuicio para las oportunidades del menor en la red. La búsqueda de la eliminación total de los posibles riesgos de la red no puede llevar a una mediación mayoritariamente restrictiva, la eliminación de todos los riesgos en la red como en cualquier otra faceta de la vida es prácticamente imposible y puede resultar contraproducente. El verdadero éxito de la mediación radicará siempre en dotar al menor de la capacidad para afrontar los riesgos y evitar que estos tengan consecuencias negativas.

\section{Discusión}

La mediación parental en el uso de internet que hacen los menores ha suscitado un gran interés en la investigación y han sido muchas las investigaciones que se han desarrollado en torno a este terreno (Livingstone et al., 2008; Kirwil et al., 2009, Haddon, 2011; Nikken, 2011; Sonck, 2011; Kersten, 2011; Durarger y Livingstone, 2012). Sin embargo, los distintos enfoques metodológicos y cuestionarios empleados hacen que sea muy complicado establecer comparaciones o paralelismos entre las distintas investigaciones.

El trabajo del grupo Generaciones Interactivas (Bringué y Sádaba, 2009), muestra una incidencia de la mediación muy inferior a la de los resultados que se presentan en este trabajo. Solo el 7\% de los menores afirma que sus padres comprueban las páginas por las que ha navegado (frente al $44 \%$ que lo afirma en este trabajo), el $11 \%$ afirma que sus padres le recomiendan lugares en los que navegar (el $49 \%$ en este trabajo), mientras que el 56\% afirma que sus padres le prohíben dar datos personales en internet (cifra que llega al 90\% en la encuesta EU Kids Online).

Varios factores pueden explicar estas diferencias. En primer lugar, es necesario tener en cuenta la diferencia en la edad de los menores estudiados en la muestra - de 10 a 18 años en el caso de Generaciones Interactivas y de 9 a 16 en el caso de EU Kids Online-. En ambas encuestas se demuestra la disminución de la incidencia de la mediación en función de la edad. Así, el hecho de contar con menores de más edad puede explicar la menor incidencia de la mediación en la encuesta de Generaciones interactivas. Por otro lado, el trabajo de campo de Generaciones Interactivas se realizó el año 2009 y el de EU Kids Online en 2010. Si bien es una diferencia de un solo año, hay que tener en cuenta que los niveles de concienciación sobre los riesgos de la red han aumentado considerablemente los últimos años. Al margen de estas cuestiones, los aspectos metodológicos difieren mucho entre el trabajo de Generaciones Interactivas y el de EU Kids Online. En la investigación realizada por Generaciones Interactivas se utilizó un muestreo por conglomerados que seleccionaba centros escolares considerando la proporción por comunidad y tipo de titularidad (pública o privada). La selección de los centros por comunidad era aleatoria, pero la selección posterior de los alumnos a encuestar se realizó a través de un "muestreo por conveniencia" (Bringué y Sádaba, 2009: 36). En total la muestra válida ascendió a 12.919 casos, de los que 9.517 eran de alumnos entre 10 y 18 años a los que se les realizó esta encuesta. Finalmente, los entrevistados tenían que responder a un cuestionario online. En el caso de EU Kids Online las muestras se estratificaron por región y nivel de urbanización y los pun-

doxa.comunicación | n 17, pp. 99-117 | 113 
tos de muestreo se seleccionaron a través de registros administrativos. Los domicilios se seleccionaron aleatoriamente a través del procedimiento de las rutas aleatorias. Este procedimiento garantiza una mayor dispersión de las unidades de análisis de la investigación que implica una reducción del error muestral (Cea D’Ancona,: 2012).

En este sentido, la encuesta de "hábitos de seguridad en los hogares con menores" (INTECO, 2011) llevada a cabo los últimos años marca un aumento continuado en la incidencia de la mediación y proporciona unos resultados más en línea con los de este trabajo. Según esta encuesta el 90\% de los padres realiza acciones que se pueden encuadrar dentro de la mediación parental activa en el uso de internet y un $60 \%$ afirma supervisar los contenidos visitados por el menor en internet.

El trabajo de Sureda, Comas y Morey (2010) también analiza el papel de las familias en el uso de internet, en este caso desde la perspectiva de las normas para el uso por parte de los menores. Si bien la presencia de normas detectada en este estudio es inferior a la que aportan los resultados de la encuesta de EU Kids Online, se observan algunas pautas similares como el escaso uso de la mediación técnica o el escaso acompañamiento de los padres a los menores en la navegación por internet.

En cualquier caso, la baja implicación de los padres en el uso que hacen los menores de internet va en la línea de lo apuntado por los investigadores del grupo AUSTICA, que señalan como, a pesar de que se habla constantemente en términos educacionales sobre alfabetización digital, las prácticas sociales digitales no se contemplan dentro de la escuela ni dentro de la casa (Busquet, Ballano, Medina y Uribe, 2012:50)

Los niveles y los patrones de uso son importantes para entender tanto los riesgos como las oportunidades porque condicionan el modo en el que el menor se expone a los factores de riesgo y porque es necesario saber si se toman las medidas de prevención necesarias. Es muy importante señalar que en tanto los niveles generales de acceso están creciendo y los dispositivos se están diversificando, las políticas de seguridad en la red han de ampliarse y diversificarse para adaptarse a este entorno tan cambiante. De manera muy particular, las políticas habrán de responder a las necesidades de protección derivadas del uso de internet a una edad cada vez más temprana, así como al uso de internet sin la supervisión de los adultos, especialmente a través de la tecnología móvil.

\section{Referencias bibliográficas}

Anderson, C.A., y Bushman, B.J. (2001): "Effects of violent video games on aggressive behaviour, aggressive cognition, aggressive affect, physiological arousal, and prosocial behaviour: A meta-analytic review of the scientific literature", Psychological Science, 12, pp. 353-359. (DOI: 10.1111/1467-9280.00366). 
Aslanidou, S. y Menexes, G. (2008): "Youth and the Internet: Uses and practices in the home”, Computers yeducation, 51(3), pp. 1375-1391. (DOI: 10.1016/j.compedu.2007.12.003).

Bringué, X. y Sádaba T. (2009). La generación interactiva en España. Niños y adolescentes frente a las pantallas. Madrid: Fundación Telefónica-Ariel. Disponible en: http://www.generacionesinteractivas.org/upload/libros/La-Generaci \%C3\%B3n-Interactiva-en-Espa\%C3\%B1a.pdf [Consultado el 17/07/2012].

Buckingham, D. (2000): After the Death of Childhood: Growing up in the age of electronic media. Cambridge: Polity Press.

Busquet, J., Ballano, S., Medina, A. y Uribe, A. C. (2012): "La dinámica de la brecha digital entre jóvenes,padres y profesores en España -proyecto AUSTICA- Grupo de investigación CONINCOM”, en García Jimenez, A. (Ed.): Comunicación, infancia y juventud. Situación de la investigación en España. Barcelona: UOC, pp. 39-56.

Cea D’Ancona, M. A. (2012): Fundamentos y aplicaciones en metodología cuantitativa. Madrid: Síntesis.

Dürager, A. y Livingstone, S. (2012): How can parents support children's internet safety? (Report EU Kids Online). Disponible en http://www2.lse.ac.uk/media@lse/research/EUKidsOnline/EU\%20Kids\%20Online\%20reports.aspx [Consultado el $17 / 07 / 2013]$.

Eurobarometro (2007): Eurobarometer on Safer Internet for Children: Qualitative Study 2007. Disponible en http://ec.europa.eu/information_society/activities/sip/surveys/quantitative/index_en.htm [Consultado el 17/07/2013]

Ferrés Prats, J., Aguaded Gómez, J. I. y García Matilla, A. (2012): “La competencia mediática de la ciudadanía española: dificultades y retos", Icono14, 10 (3), pp. 23-42.

Garmendia, M, Garitaonandia, C. Martínez, G. y Casado, M. A. (2011): Riesgos y seguridad en internet: los menores españoles en el contexto europeo. Bilbao: Universidad del País Vasco.

Garmendia, M., Garitaonandia, C. Martínez, G. y Casado, M. A. (2011): “Recomendaciones políticas de EU Kids Online I. Hacia una política basada en evidencias”, en Blanco, I. y Römer, M. (Coords.) Los niños frente a las pantallas. Madrid: Universitas, pp. 299-311.

Gentile, D. A.; Nathanson, A. I.; Rasmussen, E.E., Reimer, R. A y Walsh, D. A. (2012): “Do You See What I See? Parent and Child Reports of Parental Monitoring of Media”, Family relations, 61(3), pp. 470-487. (DOI: 10.1111/j.1741-3729.2012.00709.x).

Haddon, L (2002): “Youth and Mobiles: The British Case and Further Questions”, Estudios de Juventud, n. 57, pp. 115-124.

Haddon, L. y Silverstone, R. (1992): Information and Communication Technologies in the Home: The Case of Teleworking, Working Paper 17, SPRU CICT, University of Sussex.

Haddon, L. (2011): “Parental mediation of internet use: Evaluating family relationships”, Nordmedia Conference, 11-13 August, Akureyri, Iceland.

Hasebrink, U., Livingstone, S., Haddon, L., y Olafsson, K. (2009): Comparing children's online opportunities and risks across Europe Cross-national comparisons for EU Kids Online. London: LSE, EU Kids Online. 
Himmelweit, Hilde .T (1958): Television and the Child. New York: Oxford University Press.

INTECO (2011). Estudio sobre la seguridad de la información y la e-confianza de los hogares españoles (Informe anual 2010). Disponible en: http://www.inteco.es/Seguridad/Observatorio/Estudios/estudio_hogares_4T2010 [Consultado el 17/07/2013]

Kirwil, L., Garmendia M., Garitaonandia C. y Martínez, G. (2009): “Parental Mediation”, Livingstone, S. y Haddon, L. (Eds.): Kids Online: Opportunities and risks for children. Bristol: The Policy Press, pp. 199-217.

Livingstone, S. (2007): “From family television to bedroom culture: young people's media at home", en Devereux, E. (Ed.): Media studies: key issues and debates. London: SAGE Publications, pp. 302-321.

Livingstone, S. y Helsper, E. (2008): "Parental mediation of children's Internet use”, Journal of Broadcasting y Electronic Media, n. 52, pp. 581-599. (DOI:10.1080/08838150802437396).

Livingstone, S., y Bober, M. (2006): "Regulating the internet at home: Contrasting the perspectives of children and parents", en Buckingham y Willett, R. (Eds.): Digital Generations. Mahwah. NJ.: Erlbaum, pp. 93-113.

Livingstone, S., Haddon, L., Görzig, A., y Ólafsson, K (2011): Risks and safety on the internet: The perspective of European children. London: LSE.

Gutiérrez Martín, A., y Tyner, K. (2012): "Educación para los medios, alfabetización mediática y competencia digital”, Comunicar: Revista científica iberoamericana de comunicación y educación, n. 38, pp. 31-39.

Nathanson, A. (2001): "Parent and child perspectives on the presence and meaning of parental television mediation", Journal of Broadcasting and Electronic Media, n. 45, pp. 201-220. (DOI:10.1207/s15506878jobem4502_1).

Nikken, P. y Jansz, J. (2011): “Parental mediation of young children's Internet use”, EU Kids Online II Conference - 23 September 2011, Londres.

O’Neill, B. (2011): “Trust, safety, security: Framing EU Kids Online policy recommendations within the Digital Agenda for Europe", Presentation at Cities, Creativity, Connectivity. Annual IAMCR Congress, Kader Has University, Istanbul, 13-17 July, 2011.

Oswell, D. (1999): “The dark side of cyberspace: Internet content regulation and child protection”, Convergence: The Journal of Research into New Media Technologies, n. 5, pp. 42-62. (DOI: 10.1177/135485659900500404).

Ponte, C. Bauvens, J. y Mascheroni, G. (2009): "Children and the internet in the news: agency, voices and agendas", en Livingstone, S. y Haddon, L. (Eds.): Kids online. Opportunities and risks for children. Bristol: The Policy Press, pp.159-172.

Silverstone, Roger, Hirsch, Eric (Eds.) (1992): Consuming Technologies: Media and information in domestic spaces. London/New York: Routledge.

Sonck, N. (2011): Explaining differences in parental mediation Nathalie, September 2011, EU Kids Online Final Conference LSE. 
Sonck, N.; Nikken, P. y de Haan. J. (2011): Determinants of internet mediation: a comparison of the reports by parents and children, EU Kids Online II Conference - 23 September 2011, Londres.

Sureda, J., Comas, R. y Morey M. (2010): “Menores y acceso a Internet en el hogar: las normas familiares”, Comunicar, n. 34, pp. 135-143. (DOI:10.3916/C34-2010-03-13).

Valcke, M.; De Wever, B.; Van Keer, H. y Schellens, T. (2011): “Long-term study of safe Internet use of young children”, Computers y education, n. 57, 1, pp. 1292-1305. (DOI: 10.1016/j.compedu.2011.01.010).

Valkenburg, P., Krcmar, M., Peeters, A. y Marseille, N. (1999): "Developing a scale to assess three styles of television mediation: "instructive mediation", "restrictive mediation" and "social coviewing", Journal of Broadcasting and Electronic Media, n. 43, pp. 52-66. (DOI:10.1080/08838159909364474).

Van der Voort, T., Nikken, P. y Van Lil, J.E. (1992): “Determinants of Parental Guidance of Children's Television Viewing: A Dutch Replication Study”, Journal of Broadcasting y Electronic Media, n. 36, pp. 61-74. (DOI:10.1080/08838159209364154).

Wang, R., Bianchi, S., y Raley, S. (2005): “Teenagers' Internet use and family rules: a research note”, Journal of Marriage and Family, n. 67, pp.1249-1258.

Wolak, J., Finkelhor, D., Mitchell K. J. y Ybarra M. L. (2008): “Online 'predators' and their victims”, American Psychologist, n. 63 (2), pp. 111-128. 